\title{
Sintesis Magnesium Oksida dengan Variasi Temperatur Sintering
}

\author{
Ilma Husnah*, Astuti \\ Jurusan Fisika, Universitas Andalas \\ *ilmahusnah26@gmail.com
}

\begin{abstract}
ABSTRAK
Telah dilakukan penelitian tentang sintesis magnesium oksida $(\mathrm{MgO})$ menggunakan metode presipitasi. Nanopartikel $\mathrm{MgO}$ disintesis dengan memvariasikan temperature sintering yaitu $400^{\circ} \mathrm{C}, 500^{\circ} \mathrm{C}, 600^{\circ} \mathrm{C}$, dan $700^{\circ} \mathrm{C}$ dengan massa PEG-6000 2 g. Struktur kristal, ukuran kristal, morfologi permukaan, dan distribusi diameter partikel dari nanopartikel ini dikarakterisasi menggunakan X-Ray Diffraction (XRD) dan Scanning Electron Microscope (SEM). Dari hasil analisis pola difraksi sinar-X ditunjukkan bahwa struktur kristal $\mathrm{MgO}$ berbentuk kubik dan morfologi permukaan $\mathrm{MgO}$ berbentuk bulat (spherical). Ukuran kristal semua sampel berkisar antara 27,36 - 45,57 nm dan ukuran partikel semua sampel berkisar antara 30,41 - 95,92 nm. Hasil SEM menunjukkan semakin tinggi temperatur sinteringnya maka morfologi permukaan $\mathrm{MgO}$ semakin homogen.
\end{abstract}

Kata kunci: MgO, presipitasi, temperatur sintering, XRD, SEM

\begin{abstract}
The synthesis of magnesium oxide $(\mathrm{MgO})$ by precipitation method has been conducted. $\mathrm{MgO}$ nanoparticles are synthesized with sintering temperature variations of $400^{\circ} \mathrm{C}, 500^{\circ} \mathrm{C}, 600^{\circ} \mathrm{C}$, dan $700^{\circ} \mathrm{C}$ with 2 gr mass of PEG-6000. Crystal structure, crystallite size, surface morphology and particle diameter distribution of these nanoparticles were characterized by X-Ray Diffraction (XRD) and Scanning Electron Microscope (SEM). From X-ray patterns analysis, it is known that crystal structure of $M g O$ is cubic shape and surface morphologi of $\mathrm{MgO}$ is spherical shape. The crystallite size of all samples are approximately from $27.36-45.57 \mathrm{~nm}$. The particle size of all samples are approximately from $30.41-$ $95.92 \mathrm{~nm}$. The SEM images show that higher temperature of sintering the more homogeneous the surface morphology of $\mathrm{MgO}$.
\end{abstract}

Keywords: $M g O$, precipitation, sintering temperature, XRD, SEM

\section{PENDAHULUAN}

Nanoteknologi menghasilkan suatu nanomaterial yang pada saat ini aplikasinya sangat luas diantaranya adalah di bidang biomedis, bioteknologi, teknik ilmu material dan lingkungan. Penggunaan nanomaterial terus dikembangkan dalam dunia industri termasuk metode yang digunakan dalam menghasilkan nanomaterial tersebut untuk meningkatkan kualitas produk industri (Fernandez, 2011). Salah satu nanomaterial yang menjadi perhatian peneliti untuk saat ini adalah keramik.

Salah satu bahan keramik yang saat ini mempunyai aplikasi yang luas baik dalam dunia industri maupun penelitian adalah magnesium oksida $(\mathrm{MgO})$. Material ini memiliki konduktivitas stabil pada temperatur tinggi, titik lebur yang tinggi, tahan korosi pada temperatur tinggi serta tersedia melimpah di alam. Bahan ini juga mempunyai kelemahan, yaitu ketahanan terhadap kejutan termal dan mekanik rendah (Harefa, 2009). Kelemahan dari bahan tersebut dapat diperbaiki dengan cara mengembangkan rekayasa berstruktur nanopartikel.

Pada penelitian sebelumnya, Ibrahim (2010) telah melakukan penelitian tentang sintesis dan karakterisasi serbuk nano $\mathrm{MgO}$ menggunakan metode sol-gel dengan memvariasikan temperatur 600,700 , dan $800{ }^{\circ} \mathrm{C}$ selama 6 jam. Analisis X-Ray Difraction (XRD) dan Scanning Electron Microscopy (SEM) menunjukkan bahwa rata-rata ukuran kristal $\mathrm{MgO}$ yang didapatkan sebesar 22,7 nm dan morfologi MgO adalah nanosfera. Meenakshi (2012) juga telah melakukan penelitian tentang sintesis $\mathrm{MgO}$ dengan metode presipitasi menggunakan PVP (Polyvinil pyrrolidone) sebagai surfaktannya. Analisis SEM dan XRD menunjukkan bahwa ukuran partikel $\mathrm{MgO}$ yang didapatkan sebesar $60 \mathrm{~nm}$ dan memiliki bentuk kristal heksagonal. Pada penelitian lain, Alpionita dan Astuti (2015) melakukan penelitian tentang sintesis dan karakterisasi $\mathrm{MgO}$ menggunakan metode presipitasi. Morfologi permukaan $\mathrm{MgO}$ dengan variasi temperatur sintering menunjukkan bahwa dengan temperatur sintering yang lebih tinggi menghasilkan partikel-partikel yang semakin homogen dibandingkan morfologi dengan temperatur sintering yang rendah. 
Pada penelitian ini disintesis $\mathrm{MgO}$ dengan menambahkan surfaktan PEG-6000 (Polietilen Glikol - 6000) dan memvariasikan temperatur sintering. Variasi temperatur sintering dalam pembentukan kristal dilakukan karena senyawa $\mathrm{MgO}$ memiliki konduktivitas panas yang cukup tinggi dengan titik lebur $3073 \mathrm{~K}$. MgO disintesis dengan variasi temperatur sintering pada temperatur $400,500,600$, dan $700{ }^{\circ} \mathrm{C}$ selama 3 jam menggunakan metode presipitasi. Variasi temperatur sintering ini bertujuan untuk melihat morfologi dan ukuran partikel, dan struktur dan ukuran kristalnya.

\section{METODE}

Sintesis nanopartikel $\mathrm{MgO}$ disiapkan dengan metode presipitasi yang diawali dengan menambahkan $50 \mathrm{ml}$ dari $1 \mathrm{M} \mathrm{Mg}\left(\mathrm{NO}_{3}\right)_{2}$ dan PEG-6000 (sampel A, B, C, dan D) yang dicampurkan dan diaduk selama 8 menit pada temperatur kamar menggunakan magnetic stirrer untuk mempersiapkan $\mathrm{MgO}$. $50 \mathrm{ml}$ dari $1 \mathrm{M}$ larutan $\mathrm{NaHCO}_{3}$ perlahan-lahan setetes demi setetes dengan menggunakan pipet tetes pada kondisi pengadukan konstan. $50 \mathrm{ml}$ larutan $\mathrm{NaOH} 1 \mathrm{M}$ juga perlahan-lahan ditambahkan dan diaduk selama 3 jam tanpa mengubah parameter apapun. Setelah selesai maka hasilnya akan berbentuk bubuk endapan putih $\mathrm{MgO}$ yang sangat halus. Serbuk halus disaring dengan hati-hati menggunakan kertas saring. Hasil penyaringan tersebut kemudian dicuci secara menyeluruh dengan bantuan air suling ganda untuk membuat endapan yang bebas dari unsur asing dan menghasilkan substrat $\operatorname{Mg}(\mathrm{OH})_{2}$. Substrat $\mathrm{Mg}(\mathrm{OH})_{2}$ yang dihasilkan kemudian dikeringkan menggunakan oven selama 1 jam pada temperatur $80^{\circ} \mathrm{C}$ untuk pengeringan lengkap. Dilanjutkan dengan proses sintering dengan variasi temperatur $400^{\circ} \mathrm{C}(\mathrm{A}), 500^{\circ} \mathrm{C}(\mathrm{B}), 600^{\circ} \mathrm{C}$ (C) dan $700^{\circ} \mathrm{C}$ (D) selama 3 jam untuk memperoleh nanopartikel $\mathrm{MgO}$ tersebut. Setelah proses sintering akan dihasilkan serbuk magnesium oksida $(\mathrm{MgO})$, kemudian dikarakterisasi dengan X-Ray Diffractometer (XRD) untuk mengetahui struktur dan ukuran kristal, Scanning Electron Microscope (SEM) untuk mengetahui morfologi dan ukuran partikel.

\section{HASIL DAN DISKUSI}

\subsection{Hasil karakterisasi menggunakan XRD}

Gambar 1 menunjukan pola difraksi sampel A (dengan variasi temperatur sintering $400^{\circ} \mathrm{C}$ ), B (dengan variasi temperatur sintering $500^{\circ} \mathrm{C}$ ), C (dengan variasi temperatur sintering $600^{\circ} \mathrm{C}$ ), dan $\mathrm{D}$ (dengan variasi temperatur sintering $700^{\circ} \mathrm{C}$ ). Berdasarkan pola difraksi yang dihasilkan keseluruhan sampel dapat dilihat kandungan $\mathrm{MgO}$ yang lebih dominan di bandingkan dengan kandungan $\mathrm{NaNO}_{3}$, namun pada sampel $\mathrm{D}$ terdapat pengotor lain yaitu $\mathrm{Na}_{2} \mathrm{CO}_{3}$. Pada sampel $\mathrm{C}$ (dengan variasi temperatur sintering $600^{\circ} \mathrm{C}$ ) terlihat bahwa dihasilkan puncak yang semakin melebar dibandingkan sampel lainnya yang menandakan ukuran kristalnya semakin mengecil. Hal ini menandakan temperatur sintering yang meningkat akan menyebabkan difusi atom menjadi lebih cepat sehingga mempercepat kristalinitas dan membentuk ukuran kristal yang lebih kecil. Berdasarkan perhitungan dengan menggunakan persamaan Scherrer didapatkan ukuran kristal untuk sampel A sebesar 45,57 nm, sampel B sebesar 427,80 nm, sampel C sebesar 27,36 nm, dan sampel D sebesar 33,37 nm. Kemudian pola difraksi pada keseluruhan sampel tidak ditemukan adanya fasa PEG, hal ini menandakan PEG tidak ikut bereaksi hanya melapisi partikel $\mathrm{MgO}$ saja. 

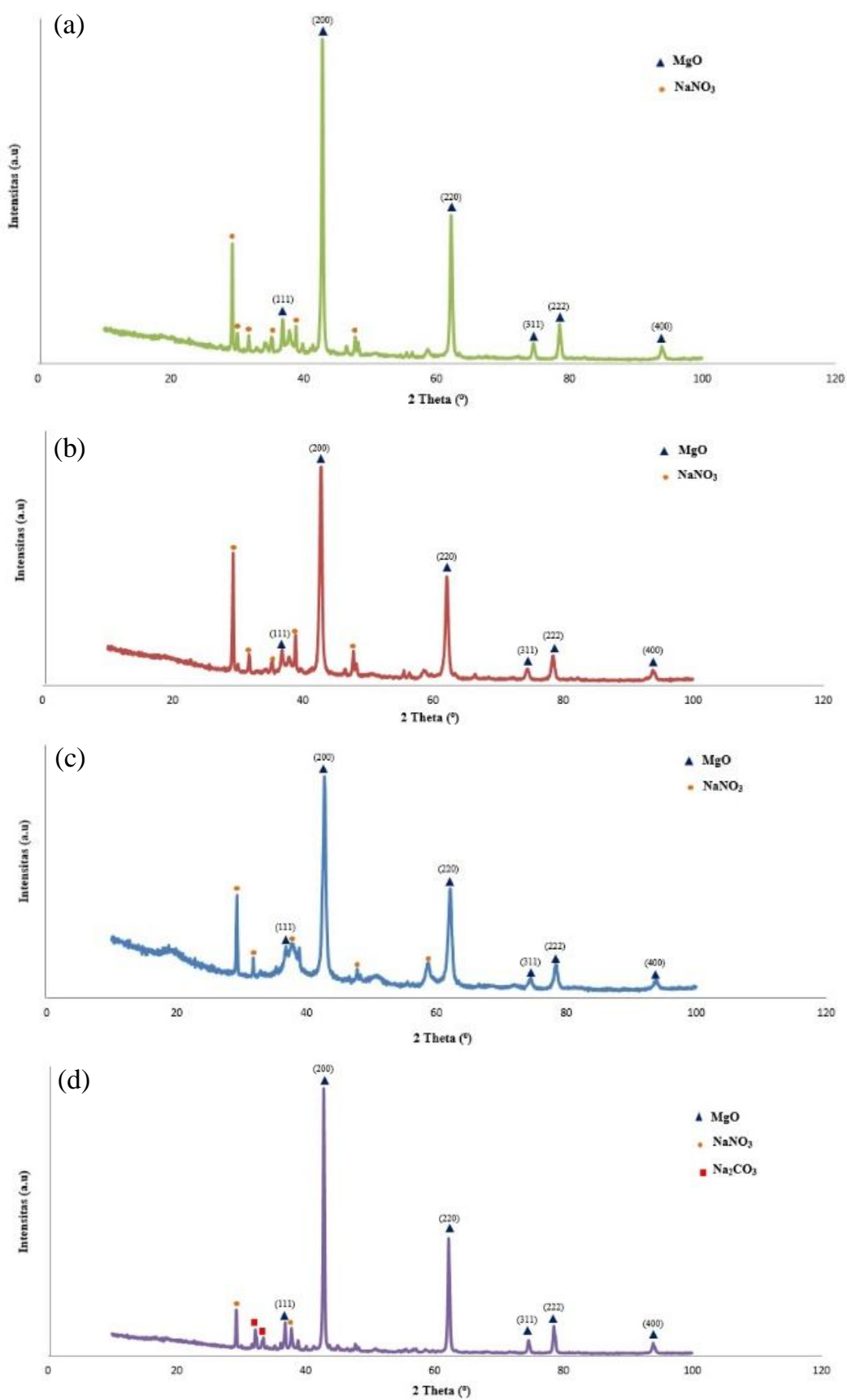

Gambar 1 Hasil karakterisasi menggunakan XRD pada (a) $\mathrm{MgO}$ dengan variasi temperatur sintering $400^{\circ} \mathrm{C}$, (b) $\mathrm{MgO}$ dengan variasi temperatur sintering $500^{\circ} \mathrm{C}$, (c) $\mathrm{MgO}$ dengan variasi temperatur sintering $600^{\circ} \mathrm{C}$, dan (d) $\mathrm{MgO}$ dengan variasi temperatur sintering $700^{\circ} \mathrm{C}$

\subsection{Hasil karakterisasi menggunakan SEM}

Morfologi permukaan dari masing-masing sampel diamati dengan menggunakan Scanning Electron Microscope (SEM). Keempat sampel yaitu sampel A(dengan variasi temperatur sintering $400^{\circ} \mathrm{C}$ ), B (dengan variasi temperatur sintering $500^{\circ} \mathrm{C}$ ), $\mathrm{C}$ (dengan variasi temperatur sintering $600^{\circ} \mathrm{C}$ ), dan $\mathrm{D}$ (dengan variasi temperatur sintering $700^{\circ} \mathrm{C}$ ) dikarakterisasi untuk mengetahui pengaruh dari variasi temperatur sintering terhadap morfologi dari nanopartikel $\mathrm{MgO}$. 

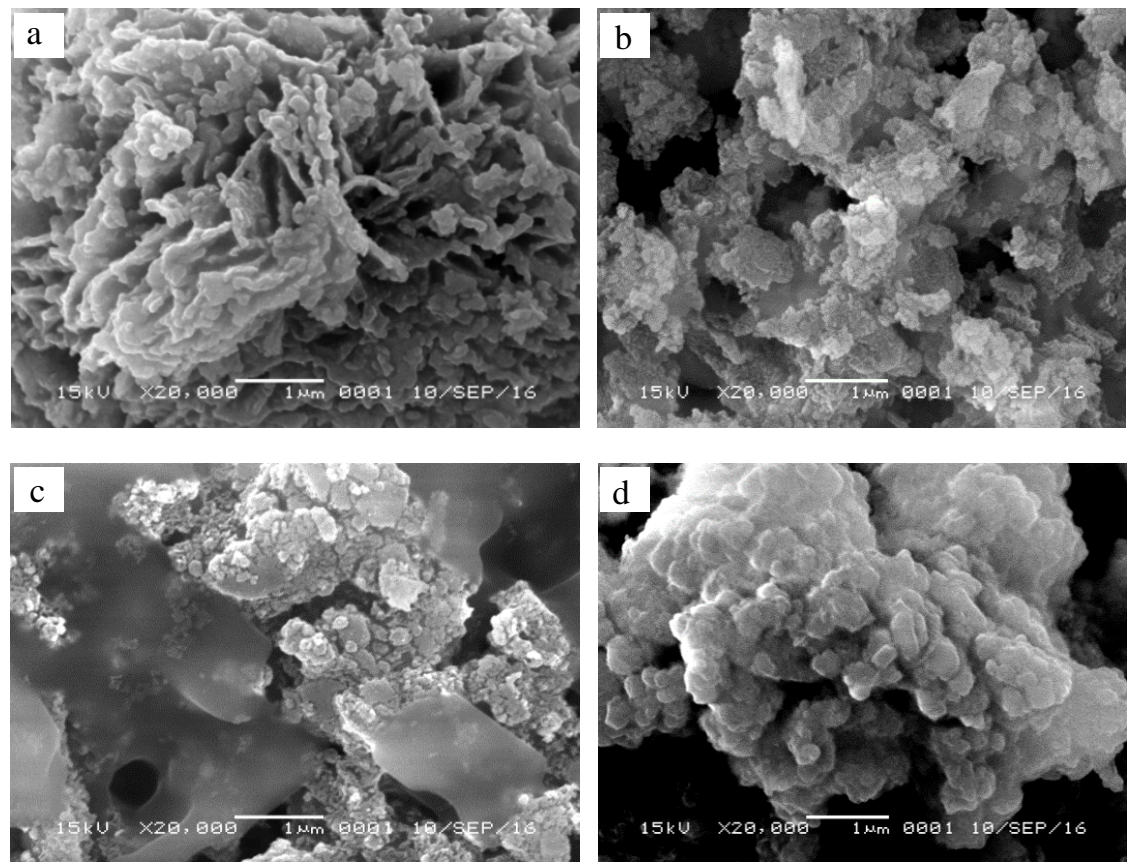

Gambar 2 Morfologi dari (a) $\mathrm{MgO}$ dengan variasi temperatur sintering $400^{\circ} \mathrm{C}$, (b) $\mathrm{MgO}$ dengan variasi temperatur sintering $500^{\circ} \mathrm{C}$, (c) $\mathrm{MgO}$ dengan variasi temperatur sintering $600^{\circ} \mathrm{C}$, dan (d) $\mathrm{MgO}$ dengan variasi temperatur sintering $700^{\circ} \mathrm{C}$

Berdasarkan variasi temperatur sintering yang telah dilakukan, morfologi partikel yang lebih baik adalah pada variasi temperatur sintering $600^{\circ} \mathrm{C}($ Gambar 2.c). Pada variasi temperatur sintering ini terbentuk partikel yang bulat pipih (spherical) dan masih banyak terdapat penggumpalan (aglomerasi) namun porositas yang terbentuk lebih sedikit dari sampel lainnya. Morfologi yang dihasilkan oleh sampel C (Gambar 2.c) lebih merata dibandingkan dengan morfologi sampel lainnya (Gambar 2). Kemudian pada komposisi ini juga dihasilkan partikel $\mathrm{MgO}$ yang lebih kecil dibandingkan dengan sampel lainnya. Ukuran partikel $\mathrm{MgO}$ Gambar 2.c berkisar antara 33,14-69,63 $\mathrm{nm}$.

\section{KESIMPULAN}

Berdasarkan penelitian yang telah dilakukan Sintesis nanopartikel $\mathrm{MgO}$ dengan memvariasikan temperatur sintering dapat mempengaruhi ukuran partikel dan menghasilkan distribusi partikel $\mathrm{MgO}$ yang seragam. Distribusi yang paling seragam didapatkan pada variasi temperatur sintering $600^{\circ} \mathrm{C}$ dengan ukuran partikelnya $33,14-69,63 \mathrm{~nm}$.

\section{DAFTAR PUSTAKA}

Alpionita, P. dan Astuti., 2014, Sintesis dan Karakterisasi Magnesium Oksida (MgO) dengan Variasi Massa PEG-6000, Jurnal Fisika Unand, Vol. 4, No. 2, Hal: 167-172, Jur. Fisika Unand

Fernandez, B.R., 2011, Sintesis Nanopartikel, (online), http://bennyriofernandez.blogdetik.com, diakses pada tanggal 5 april 2016.

Harefa, F., 2009, Pemanfaatan Limbah Padat Pulp Grits Dan Dregs Dengan Penambahan Kaolin Sebagai Bahan Pembuatan Keramik Konstruksi, Skripsi, Universitas Sumatera Utara, Medan.

Ibrahim, N., 2010, Synthesis and Characterization of MgO Nanopowders by Sol-Gel Method Incorporated Reflux Approach, Tesis, Bachelor of Science Chemistry, Faculty of Applied Sciences, Universiti Teknologi Mara, Selangor.

Meenakshi, D., 2012, Synthesis and Characterization of Magnesium Oxide Nanoparticles, Elixir International Journal, RVS School of Engineering and Technology, Vol.50. No.9: hal $1-3$. 